\title{
Common Sense, Ontology and Time: A Critique of Lynne Rudder Baker's View of Temporal Reality $^{*}$
}

L. Nathan Oaklander

University of Michigan-Flint

Department of Philosophy

303 E. Kearsley Street

Flint, MI 48502

USA

lno@umflint.edu

Article info

CDD: 115

Received: 24.11.2016; Accepted: 25.11.2016

DOI: http://dx.doi.org/10.1590/0100-6045.2016.V39N4.NO

Keywords:

BA-theory

R-theory

B-series

McTaggart

growing universe

absolute becoming

\begin{abstract}
The aim of this paper is twofold: First, to critically discuss Lynne Rudder's Baker BA-theory of time, and second to contrast it with the R-theory (after Russell). In the course of my discussion I will contrast three different methodological approaches regarding the relation between common sense and ontology; clarify Russell's authentic view in contrast to the Btheory which is McTaggart's misrepresentation of Russell, and consider how the R-theory can respond to objections Baker makes to eternalism (as she understands it).
\end{abstract}

*I wish to thank Lynne Rudder Baker, Emiliano Boccardi, and Erwin Tegtmeier for their incisive comments on an early draft of this paper.

Manuscrito - Rev. Int. Fil. Campinas, v. 39, n. 4, pp. 117-156, out.-dez. 2016. 


\section{Introduction}

Lynne Rudder Baker, who initially defended Adolf Grünbaum's version of the B-theory $(1976,1974)$, has "since come to my senses" (2007, p. 159). Baker currently maintains that in addition to the B-series and B-relations, the A-series and (mind-dependent) A-properties are irreducible features of reality; a view she calls "the BA theory of time" (2007, p. 149). In this paper I intend to indicate the errors that lead her to the BA-theory, and then turn to the problems with the view itself. Diagnosing Baker's mistakes is instructive in clarifying Russell's authentic view in contrast to the B-theory which is McTaggart's misrepresentation of Russell, but has nevertheless been accepted generally as Russellian. First, a brief discussion, to be expanded in the course of this paper, of differences between the Russellian theory of time ("Rtheory" for short), and standard B-theoretic accounts as sometimes understood by defenders and critics alike. ${ }^{1}$

On typical interpretations, the ontology of B-time is construed as antirealist because it denies that temporal passage is an objective, mindindependent feature of reality. For that reason, B-relations and the B-facts they enter into, that alone constitute the foundation of the B-theory of time, are "nontransient" and static in that what appears to be the flow and flux of events in time -time's dynamism-is an illusion that would not exist without consciousness. On the other hand, R-relations as given in experience are not static, but dynamic, and are the basis of our experience of transition or passage from say, one sound to another when we hear a doorbell ringing, or watch the movement of a second hand of a watch. In addition, on standard (reductionist) B-theories, B-relations are analyzable in terms of causal relations whereas the $\mathrm{R}$-theory takes $\mathrm{R}$-relations as primitive and unanalyzable, relational universals that can be directly experienced. For that reason, Russellian temporal relations are external relations, since "there are such facts as that one object has a certain relation to another, and that such facts cannot be reduced or inferred from, a fact about the one object only together with a fact about the other object only: they do not imply that the

${ }^{1}$ I have discussed the R-theory in Oaklander (2015), (2014a), (2014b) and (2012). For a good discussion of McTaggart's misinterpretation of the Russellian view see Tegtmeier (2012).

Manuscrito - Rev. Int. Fil. Campinas, v. 39, n. 4, pp. 117- 156, out.-dez. 2016. 
two objects have any complexity, or any intrinsic property distinguishing them from two objects which do not have the relation in question" (Russell, 190607, pp. 139-40). In other words, R-relations are neither analyzable in terms of A-properties of their terms nor do they depend on A-properties. Indeed, on the R-theory there are no such properties. A last difference is particularly important for the discussion to follow. The B-theory is often identified with McTaggart's (1921) misinterpretation of Russell, according to which Brelations are unchanging and $\mathrm{B}$-facts are permanent in that if $a$ is ever earlier than $\mathrm{b}$, then $a$ is always earlier than $b$. In contrast, R-theorists do not believe that either R-relations or R-facts exist in time, much less at every time, as McTaggart's interpretation implies. 'Earlier than' is a timeless yet dynamic temporal relation. It is timeless because it does not exist in time; as a term of a temporal relation. It is dynamic because it is the ground of our experience of successively existing temporal objects that exist TENSElessly, that is, without TENSED A-properties. Similarly, time, understood as a Russellian series composed of a conjunction of R-facts, is timeless. This view gives some meaning to an aphorism I favor, namely, time is timeless, or eternal in just this sense: though time contains temporal relations, time does not exemplify them. With this background we can turn to some methodological issues that should help us understand Baker's view of time.

\section{Methodology and Ontology}

In The Metaphysics of Everyday Life Baker (2007) argues that what is manifest in everyday life, language and experience should be given full ontological status as "irreducibly real." She applies her commonsense approach to many metaphysical topics such as the nature of persons and personal identity, causation and time to name a few. With regard to time Baker says, "The everyday world is a temporal world: the signing of the Declaration of Independence is later than the Lisbon earthquake; the Cold war is in the past, your death is in the future" (2010, p. 27; emphasis added). Baker thus follows McTaggart $(1908,1921)$ by maintaining that we ordinarily conceive of time in terms of the A-series of events ordered by the transient (changing) Aproperties of pastness, presentness and futurity and by the B-series of events ordered by the nontransient (unchanging) static B-relations of earlier/later

Manuscrito - Rev. Int. Fil. Campinas, v. 39, n. 4, pp. 117- 156, out.-dez. 2016. 
than and simultaneity. She concludes that we require both the B-series and the A-series as irreducibly real to understand all the temporal facts. To make clear Baker's views on the relation between commonsense or everyday life, and her philosophy of time, I contrast three different approaches to commonsense and ontology, beginning with G. E. Moore.

According to the first stance, it is admitted by all concerned that there is no disagreement concerning the common sense facts that are expressed in a pre-analytic ordinary language. Those facts must, however, be distinguished from the ontological facts that are their analysis. The everyday world contains objects and facts about those objects that we all know to be commonsensically true, and no one wishes to dispute them. Thus, for example, in his symposium paper "Is there 'Knowledge by Acquaintance'?" Moore (1919) argues that when Russell uses the term 'acquaintance' he is generally appealing to a relation that we have to objects of sense when we perceive, hear, touch, taste or smell something. In this sense, according to Moore, it is quite clear that we are acquainted with objects. Thus, when Neutral Monists claim that when two objects are experienced by the same individual there is, strictly speaking, nothing which experiences either of them, they should not be viewed as denying acquaintance with sense data. On Russell's view of acquaintance Neutral Monism is mistaken since he holds that when two objects are experienced by the same person, there is a subject $\mathrm{S}$, distinct from the objects experienced that does the experiencing. These are two different analyses of what is meant by "acquaintance." Moore continues,

I do not, when I assert that I certainly am acquainted with sense-data, in the least wish to imply that the Neutral Monists are wrong in their analysis of the facts: I only wish to assert an indisputable fact of the kind they are trying to analyse. (Moore, 1919, p. 186)

Generally, when Russell has uses the term "acquaintance", he is using it simply as a name for an indisputable fact; a fact that nobody has ever thought of disputing. Moore proceeds,

What I wish to make clear is that Neutral Monists do not for a moment deny the existence of what I am calling acquaintance with sense-data, and what I take Mr. Russell to generally to have meant by that term. All that they do is to offer a particular analysis of the kind of fact which

Manuscrito - Rev. Int. Fil. Campinas, v. 39, n. 4, pp. 117- 156, out.-dez. 2016. 
I express by saying that I am acquainted with sense-data, without, of course, denying, any more than anybody else does, the existence of facts of the kind they are analyzing. (Moore, 1919, p. 185)

There are many different particular analyses of the indisputable facts that can, of course, be disputed, but what cannot be disputed, much less denied, according to Moore, are the common sense facts philosophers seek to analyze or, if I may so put it, provide an ontological ground. Moore reaffirms this position in the following passage:

I am not at all sceptical as to the truth of such propositions as "The earth has existed for many years past." "Many human bodies have each lived for many years upon it," . . . on the contrary, I hold that we all know, with certainty, many such propositions to be true. But I am very sceptical as to what, in certain respects, the correct analysis of such propositions is. (Moore 1925, p. 52)

This is a clear and unambiguous bifurcation between commonsense and ontology. Baker, on the other hand, builds into common sense a definite ontology, as I shall demonstrate below.

In his earliest writing on time C. D. Broad (1921), makes a point about the relationship between common sense and ontology analogous to Moore's. To the question Is time real? Broad claims that it must be answered in the affirmative. What McTaggart and others who argue for the unreality of time have shown, at most, is that their analyses of time do not correspond to anything in the world. However, to demonstrate that an analysis or theory of time is mistaken does not demonstrate that the temporal phenomena with which the analysis is concerned does not exist or that there is nothing in reality that is its ground. The phenomena that cannot be doubted may comport with a different analysis.

In the following passage Broad emphasizes that temporal succession and duration are distinctly given to us in introspection and perception and for that reason the reality of time can hardly be doubted:

It is a matter of direct inspection that the immediate objects of some of our states of mind have temporal characteristics. It is as certain that one note in a heard melody is after another in the same specious present and that each has some duration as that some objects in my

Manuscrito - Rev. Int. Fil. Campinas, v. 39, n. 4, pp. 117- 156, out.-dez. 2016. 
field of view are red or square and to the right or left of each other. It is then quite certain that some objects in the world have temporal characteristics, viz: the immediate objects of some states of mind. Now it is also certain that these objects exist at least as long as I am aware of them, for in such cases I am obviously not aware of nothing. Hence there cannot be anything self-contradictory in the temporal characteristics found in these objects, for otherwise we should have to admit the existence of objects with incompatible characteristics. Hence there is no obvious reason why temporal characteristics should not also apply to what is not the immediate object of any state of mind. It follows, then, that criticism cannot reasonably be directed against temporal characteristics as such, but only against the descriptions that we give of the temporal characteristics of experienced objects, and the conclusions that we draw from them or the constructions that we base on them. ... If we suppose that such criticisms are successful.... The only justifiable conclusion would be that one particular way of describing and extending the temporal characteristics of experienced objects is unsatisfactory, and that it behooves us to look for a better one. This point has not commonly been grasped by philosophers who claimed to disprove the reality or time. (Broad 1921, p. 151; emphasis added.)

Broad's point is that temporal phenomena are undeniable, for it is certain that "some objects in the world have temporal characteristics" (1921, p. 151). What is open to dispute is the proper description or ontological analysis of those characteristics, and for that reason, those who deny a certain ontology of time should not be understood as denying the reality of time, but as proposing an alternative theory of the real truth that the common sense phenomenological or linguistic descriptions are a vague shadow.

There is a second stance that presents a more ontologically loaded view of commonsense that agrees there are certain indisputable facts based on everyday life, for example, that the Self exists, but builds into common sense a certain ontological analysis of the Self. In Broad's discussion of the distinction between Central (pure ego) and Non-Central theories (bundle theory) of the unity of the mind, he claims that the indisputable facts strongly suggest a particular analysis of the self:

The prima facie presumption in favour of Central theories and against Non-Central theories is the common usage of language, which strongly suggests the existence of a Centre. We say: "I am thinking of this book,

Manuscrito - Rev. Int. Fil. Campinas, v. 39, n. 4, pp. 117- 156, out.-dez. 2016. 
and wanting my tea, and feeling tired, and remembering the tie that my friend wore yesterday." This certainly suggests that "I" is the proper name of a certain existent which stands in a common asymmetric relation to all those contemporary mental events. We say further: "I, who am now doing and feeling these things, was yesterday doing, thinking, wanting, and feeling such and such other things." And this certainly suggests that "I" is the proper name of something which existed and was a centre yesterday as well as to-day. ... Now, I am not suggesting that we should accept a theory because it seems to be implied by the statements of plain men. God forbid! But I do suggest that any satisfactory theory must account for the fact that plain men and philosophers in ordinary life express themselves in language which strongly favours one alternative. Now, as I have said in Chapter IV, I can quite understand that a unity of centre might appear to be a pure unity of system if the Centre were such that it could not be directly inspected. But I cannot imagine any reason why what is in fact a pure unity of system should appear to be a unity of centre. That the mind does appear to be of the latter kind seems pretty certain. And I think that this fact must be regarded, pro tanto, as favouring Central Theories. (Broad 1925, pp. 584-85; emphasis added.)

For Broad there is an implicit ontology in the concepts we employ in ordinary life that must be given weight, but it does not require that the correct ontology is to be found in common sense. One can reject that analysis if the facts for which it is introduced can be explained otherwise, and the original analysis is, for example, dialectically untenable.

Thus, Broad differs from Moore in thinking that common sense facts strongly suggest or even implies a certain theory or analysis of the concept or phenomena under investigation, but agrees with Moore in maintaining that one can deny the analysis embedded in common sense without denying the indubitable facts in question. As Broad puts it,

I think there is very little doubt that the world "self," as commonly used, implies something like the Pure Ego theory of the structure of those entities which we call "selves." Hence anyone who rejects the Pure Ego theory is, in one sense, "denying the reality of the self." But, if he offers an alternative analysis, which does equal justice to the peculiar unity which we find in the things called "selves," he is, in another sense, "accepting the reality of the self." Whenever one

Manuscrito - Rev. Int. Fil. Campinas, v. 39, n. 4, pp. 117- 156, out.-der. 2016. 
particular way of analyzing a certain concept has been almost universally, though tacitly, assumed, a man who rejects this analysis will seem to others (and often to himself) to be rejecting the concept itself. (Broad 1924, p. 94-95; cf. Broad, 1957: 791).

Broad agrees with Moore in claiming that this would be a mistake, since the common sense view that the self exists cannot be denied even if the Pure Ego theory can be.

A third way of understanding common sense is to treat it as not only containing indubitable facts, but also identifying those ordinary facts with a certain ontology. Baker seems to be sympathetic with this view since she maintains manifest objects and everyday facts reflect the metaphysics of everyday life and are irreducibly real. Baker claims that "the term 'irreducibly real' and its variants refer to objects that belong in ontology: objects that exist and are not reducible to anything "else"' (Baker, 2007, p. 4). Included in an "ontological account" of the everyday world is a "complete inventory of what exists" (2007, p. 3). "A complete ontology—comprising everything that is irreducibly real—will include manifest objects like tables" (2007, p. 4).

In other words, the distinction between the manifest objects we encounter in everyday life and ontology is much more intimate than in Moore, where there is virtually no connection, or in Broad, where the ontology is strongly suggested by language, but can be rejected. For Baker, common sense is not ontologically neutral, nor does language and experience merely provide pro tanto reasons to support one rather than another ontology. The shared world that we encounter, and is given to us in our experience, and reflected in everyday discourse represents a specific ontology an irreducible reality the indubitability of which overwhelms arguments that can be given against it. As Baker puts it:

In sum we have overwhelmingly greater reason to believe in the irreducible reality of ordinary objects and properties than to believe in any theory that denies that they are irreducibly real. The evidence of our senses, of which the commonsense tradition avails itself, trumps arcane arguments leading to anti-commonsense conclusions cut off from anything we can confirm in experience. $(2007$, p. 9)

Manuscrito - Rev. Int. Fil. Campinas, v. 39, n. 4, pp. 117- 156, out.-dez. 2016. 
This strongly suggests that not only does common sense have an articulate ontology, but that those who deny the ontology are thereby denying our common sense beliefs and experience, and are therefore to be rejected.

However, there are other passages where her position is ambiguous. For example, Baker says,

I take everyday discourse about ordinary things not only to be largely true, but also to mean what speakers think it means. Unless there is some reason to do otherwise, I take what we commonly say (e.g., "it's time to get your passport renewed," or "The fish today is fresh") at face value. I do not systematically reinterpret ordinary discourse in unfamiliar terms, nor do I suppose that ordinary discourse is defective or inferior to some other (imagined) regimented language. (2007, p. 4; emphasis added.)

On the one hand, this passage suggests that Baker does not distinguish between grammatical form in ordinary language and the logical form (or analysis) in an ontologically perspicuous language, thus supporting my interpretation of her reading off from ordinary discourse an ontology. On the other hand, this passage appears to be compatible with Broad's second stance. In characterizing Broad's stance, I said that "One can reject that analysis if the facts for which it is introduced can be explained otherwise, and the original analysis is, for example, dialectically untenable." Baker's clause "Unless there is some reason to do otherwise," appears to go in this direction. Therefore, perhaps Baker is not adopting a third view of the relation between common sense and ontology, but is simply giving more weight to common sense in an otherwise Broadian spirit about the relationship. ${ }^{2}$ For my purposes it is not important to argue that all of her arguments rests on the identification of common sense facts, or Moorean truths, with ontological facts or irreducible temporal facts, but I will endeavor to demonstrate that in some of her central arguments for the BA theory, she does adopt the stronger third stance. Before I turn to that task, however, I want to suggest my view regarding the methodological positions just mentioned.

There are, it seems to me, three questions that need to be separated. First, do our common sense beliefs about time suggest a specific metaphysics of

${ }^{2}$ Emiliano Boccardi brought this point to my attention.

Manuscrito - Rev. Int. Fil. Campinas, v. 39, n. 4, pp. 117- 156, out.-dez. 2016. 
time? Second, if they do, is Baker's description of that metaphysics pro tempore, suggested by everyday life. Third, does Baker's view of temporal reality -the BA view of time and mixed view of time and existence-provide a dialectically adequate ground of the temporal beliefs, language and phenomena it seeks to explain? I think the answer to all three questions is "no." There are ordinary temporal beliefs that are undeniable, for example, that I had my breakfast before I had my lunch; that I am sad the meeting is starting and happy that my headache ceased to exist; that I no longer have the headache; or that much time has passed since we last met. Clearly these beliefs involve temporal concepts, "earlier than," "now" "ceased to exist" "the passage of time," but what is the temporal reality that falls under those concepts, how are those notions are to be interpreted or analyzed? These are important questions, but I don't think the irreducible realities that are required to answer them, and thereby provides an ontological ground for ordinary temporal beliefs and experience, is implicit in common sense that is, I submit, ontologically neutral. For that reason, I don't think the second question should arise since it implies that common sense has a specific metaphysics. To put my point differently, one can agree with Baker that for example, it is manifest in our experience that "we cannot imagine living in a world without the passage of time" (2007, p. 157), but it does not follow that the common sense fact that time passes or that language contains tenses reflects or endorses an A-theoretic account of the ontological facts. Nor does it follow that to deny the A-series is to deny the passage of time or common sense. Thus I am sympathetic with the first stance regarding the relation between common sense and ontology. This position is nicely stated by Russell:

The process of sound philosophizing, to my mind, consists mainly in passing from those obvious, vague, ambiguous things, that we feel quite sure of, to something precise, clear, definite, which by reflection and analysis we find is involved in the vague thing that we start from, and is, so to speak, the real truth of which that vague thing is a sort of shadow. (1918, p. 179-80)

Those ambiguous beliefs that we feel quite sure of, upon reflection and analysis, are often seen to be incompatible and give rise to paradox. The task of philosophy is to show how, through reflection and analysis, the prima facie

Manuscrito - Rev. Int. Fil. Campinas, v. 39, n. 4, pp. 117-156, out.dez. 2016. 
paradoxes involved in our everyday beliefs or common sense facts, can be resolved through a dialectically adequate ontological analysis of the data in question.

Russell seems to explicitly follow this methodology in his attempt to provide a satisfactory analysis of the subject and its relation to the object experienced since he says,

Before embarking on our analysis let us again take stock of those relevant facts which are least open to doubt. From the diversity of philosophical theories on the subject, it is evident that the true analysis, whatever it may be, cannot itself be among the facts that are evident at once, but must be reached, like a scientific hypothesis, as the theoretic residue left by the comparison of data. Here, as in philosophy generally, it is not the few logically simplest facts that form our data, but a large mass of everyday facts, of which the analysis offers fresh difficulties and doubts at every step. For this reason, if we wish to start with what is undeniable, we have to use words, at first, which, though familiar, stand in need of a dissection and definition only possible at a later stage." (Russell, 1914: p. 160.)

It should not be surprising, therefore, as I shall attempt to demonstrate, that Baker's adopting the third stance and thereby taking common sense temporal facts to be ontologically irreducible, leads to difficulties. What then are the common sense temporal facts that Baker begins with? To answer that question I shall turn to her BA-theory of time.

\section{The BA-Theory of Time}

For Baker, beliefs that are manifest in daily life reflect an irreducible reality and should be taken as metaphysical fact. What then are the manifest temporal facts, and hence the ontology associated with them? She claims that the A- and B-series, as McTaggart conceives of them, are both necessary, and neither alone sufficient, to understand all everyday temporal facts. In characterizing the A- and B-series Baker says:

Events change with respect to their A-properties (pastness, presentness and futurity). For example, the death of Queen Anne was

Manuscrito - Rev. Int. Fil. Campinas, v. 39, n. 4, pp. 117- 156, out.-dez. 2016. 
once in the future, then it was present, and then past. So there are really many different A-series, not just one. By contrast there is just a single B-series. For example, if the signing of the Declaration of Independence is later than the Lisbon earthquake, then the signing is always later than the Lisbon earthquake. The term "tenseless" refers to the fact that B-relations between events do not change over time: once "earlier than" always "earlier than." (2007, p. 143; emphasis added.)

The definitive difference between the A- and B-series is this: Aproperties are transient and B-relations are not. (2007, p. 144)

I shall return to Baker's characterizations of the A- and B-series since they give rise to trouble, but first I want to briefly state the reasons why, to be discussed in more detail below, according to Baker, our everyday language, thought and experience of the world - the world that we encounter and confirm in our experience-is necessarily A-theoretic. The world contains "the paradigmatic temporal properties of past, present and future, along with the ongoing nows that order our experience" (2007, p. 42). There are temporal facts such as "this is the $21^{\text {st }}$ century or that that social services in the US used to be more secure than they are now" (2007, p. 30) that cannot be understood apart A-properties. Furthermore, events changing their temporal properties - the passage of time "is required for many kinds or ordinary phenomena - for making and executing plans, for regret, for making sense of ourselves and the world" (2007, p. 30). Indeed, Baker maintains that "We cannot imagine living in a world without the passage of time" (Baker 2010, p. 34). Thus, our language, experience and thought about the world is inseparable from the A-series, and for that reason, an ontology of time that eliminates A-theoretic transiency is incompatible with the world as it is given to us. For that reason, a B-series ontology alone such as eternalism, is incompatible with our everyday common sense beliefs and must be rejected. In addition, an adequate account of time must explain the relation between time and existence that supports "the commonsense view that the world exhibits ontological novelty. ... The world changes ontologically over time as new objects like Socrates and new kinds like dinosaurs come into existence" (2007, p. 233).

Manuscrito - Rev. Int. Fil. Campinas, v. 39, n. 4, pp. 117- 156, out.-dez. 2016. 
To sum up, Baker takes one half of Moore's defense of common sense for granted, namely, we know common sense temporal facts that nobody wishes to dispute. Baker builds into those indisputable common sense facts an ontology of time that includes:

An A-series whose terms have the transient A-properties of pastness, presentness and futurity; "a world saturated with A-series temporality" (2007, p. 153).

The passage of time, objects or events as they move from the future to the present and into the past generating "many different A-series and not just one" (2007, p. 145)

B-series composed of B-relations of simultaneity and succession that are static, unchanging B-facts such that once earlier than always earlier than.

Coming into existence is the ground of the world changing ontologically by exhibiting ontological diversity and ontological novelty.

These phenomena are important to us, and since no B-theoretic ontology, for example, eternalism, and no A-theoretic ontology, for example, presentism or the growing block universe alone can provide a complete account of all manifest temporal facts, a new BA theory of time is required. Thus, Baker says "I am convinced that we require both the A-series and the B-series to understand all the temporal facts. Neither the A- nor the B-series can be eliminated in favor of the other." (2007, p. 145)

My aim is to take the B-series as basic, but to jack up the A-series so that it too reveals an aspect of the nature of time. According to the BA theory of time, time has two irreducible aspects: one that depends on there being self-conscious entities (the aspect of the A-series, the ongoing now) and one that does not depend on self-conscious entities (the aspect of the B-series, simultaneity and succession). The BA theory will show how these two aspects are related. (Baker 2010, p. 31)

Whether our pre-analytic ordinary beliefs, experiences and language about time can be consistently explained by means of the ontology of time Baker

Manuscrito - Rev. Int. Fil. Campinas, v. 39, n. 4, pp. 117- 156, out.-dez. 2016. 
propounds is an important issue that will be one main of this paper. The other, to be considered in the final section is whether Baker's arguments against the B-series and Eternalism apply to the R-theory. The appropriate place to start these inquiries is with a more detailed examination of her understanding of the A-series and the B-series.

\section{The Mind Dependence of the A-series}

For Baker the A-series consists of events ordered by the properties of pastness, presentness and futurity (in different degrees). Since the past and the future can be understood in terms of what is earlier or later than the NOW, the question Baker addresses is: What is it for a time or event to be now or in the present? She says,

Modifying the view of Adolf Grünbaum, I say that an event's occurring now depends on someone's being judgmentally aware of it now. (Judgmental awareness is "awareness that": if you are aware that you are feeling something soft, then you are judgmentally aware of feeling something soft.) Consider, for example, a sudden snap of my fingers. The following are sufficient for your hearing the finger snap's occurring now:

You hear the snap.

You are now judgmentally aware of hearing something.

Your judgmental awareness is simultaneous with your hearing the snap.

Because you're hearing the snap is (nearly) simultaneous with the snap, the snap also occurs now. The finger snap occurs now in virtue of someone's being judgmentally aware (now) of hearing something, together with the simultaneity of the judgmental awareness with hearing the snap. (2007, p. 150)

Thus, for Baker the experience of an event's occurring now involves a judgmental awareness that takes as its object the experience of, say, perceiving of a cloud passing over the treetops. In virtue of the simultaneity of the judgmental awareness (or act of self-consciousness) with the mental act of perception, and the (nearly) simultaneity of the object with the act, the act, the object and anything simultaneous with the object perceived is present.

Manuscrito - Rev. Int. Fil. Campinas, v. 39, n. 4, pp. 117- 156, out.-dez. 2016. 
For Baker, judgmental awareness is primitively NOW. "All our selfconscious awareness is experienced as being present. Occurring now or in the present is a primitive property of all judgmental awareness at the time of the judgmental awareness" (2007, p. 151). She continues,

Everything that a self-conscious being is aware of - her own thoughts, her remembering, what someone else is saying, that she is about to go onstage, that the driveway needs to be shoveled, what have youeverything is always experienced as being present. Indeed, it is constitutive of our conscious lives that they are ordered by the Aseries' ongoing nows.

Anything that we self-consciously experience is perforce ordered by an A-series, but the A-series cannot stand alone. The BA theory takes the B-series to be basic - basic, but not exclusive or exhaustive. It is also part of the nature of time that any self-conscious experience hasmust have-A-properties. (2007, p. 152)

Baker is convinced that the world as we encounter it is "temporally ordered by ongoing nows-indeed, as saturated with A-series temporality" (2007, p. 153), but I don't think the existence of an A-series ontology follows from the mind-dependence of becoming. First, note that Grünbaum views his theory of the mind-dependence of becoming as being a descendent of Russell in his classic paper "On the Experience of Time" (1915). Indeed, Grünbaum aligns himself with

those of us who claim with Russell that 'past, present and future arise from time-relations of subject and object, while earlier and later arise from time-relations of object and object. (Grünbaum 1971, pp. 21516, Russell 1915, p. 174)

To say that past, present and future arise from time relations between subject and object implies that they are "subjective" or "mind-dependent," but it does not imply that those relations give rise to monadic A-properties minddependent or otherwise. Indeed, Grünbaum says that "I am not assuming that nowness is a sensory quality like red or sweet but only that nowness and sensory qualities alike depend on awareness.” (Grünbaum 1971, pp. 216)

Clearly, for Russell there are no non-relational A-properties, but we do have experience of the present. He refers to "mental time [as] the time which

Manuscrito - Rev. Int. Fil. Campinas, v. 39, n. 4, pp. 117-156, out.-der. 2016. 
arises through relations of subject and object" and characterizes our experience of the present as follows:

(1) Sensation (including the apprehension of present mental facts by introspection) is a certain relation of subject and object, involving acquaintance, but recognizably different from any other experienced relation of subject and object.

(2) Objects of sensation are said to be present to their subject in the experience in which they are objects.

(3) Simultaneity is a relation among entities which is given in experience as sometimes holding between objects present to a given subject in a single experience.

(4) An entity is said to be now if it is simultaneous with what is present to me, i.e. with this, where "this" is the proper name of an object of sensation of which I am aware. (Russell, 1915, p. 174-75)

On the Russellian analysis in order to be aware of the presence of an experience we must have a second experience involving an experience of our experiencing of an object. In having acquaintance with an object we are aware of the presence of the object for objects given in sensation (which is a form of acquaintance) are present, and the presence of an experience is also a relation between subject and object. As Russell puts it:

This second experience must involve presence in the sense in which objects of sensation and perception are present and objects of memory are not present. Let us call this sense $P$. Then it is necessary that a subject should have relation $P$ to an object which is itself an experience, which we may symbolize by $\mathrm{S}-\mathrm{A}-\mathrm{O}$. Thus we require an experience which might be symbolized by

$$
\mathrm{S}-\mathrm{P}-(\mathrm{S}-\mathrm{A}-\mathrm{O}) \text {. }
$$

When such an experience occurs, we may say that we have an instance of "selfconsciousness", or "experience of a present experience". (1915, p. 166)

For Russell, the presence of an object or the experience of an object as being present does not involve presentness. He maintains that the presence of an object involves the perceptual experience (or sensation) of an object, but neither the presence of the object, nor the presence of the experience of an object requires the exemplification of the non-relational property of presentness. If we are conscious of both the object and the experience (perception) of the object, as we are when we perceive it, then the object and the experience are experienced as present, but there is no additional monadic

Manuscrito - Rev. Int. Fil. Campinas, v. 39, n. 4, pp. 117-156, out.-dez. 2016. 
temporal property of presentness over and above the temporal relation of simultaneity between the object and the act and the consciousness of the experience. Thus, for Russell, there is something in reality that corresponds to our experience of the present and in that sense he does give ontological status to "the present," but the analysis does not require TENSED properties.

It is worth noting that some recent B-theorists and their critics agree that on the B-theory mind-dependent A-properties are appearances that are not real in and of themselves, but are illusions of reality (see Dainton (2012) and Dolev (2007)). I do not think this is Grünbaum's view and it certainly is not Russell's. Nor is it required by our experience of time. Baker, on the other hand, claims that although A-properties and the A-series are mind-dependent they are just as real and irreducible as the mind-independent B-series and Brelations:

We self-conscious beings are part of reality. We self-conscious beings contribute to what there is.... What we contribute to temporal reality is the A-series: 'nowness' is a product of self-consciousness, but no less part of the reality of time for all that. ... The world that we interact with is ordered temporally by both the B-series and the Aseries. The Cold War (tenselessly) concludes in 1989; the Cold War is in the past. These are both temporal facts. (2007, p. 153).

It is agreed by all that these are common sense temporal facts, but by identifying them with the BA theory that takes the B-series and the A-series as basic, irreducible ontological facts, Baker adopts the third stance regarding the connection between common sense and ontology. We have discussed Baker's view of the A-series, so before considering the viability of the BA theory, we need to discuss her conception of the B-series.

\section{The B-series and the Temporal Principle}

Regarding the B-series Baker follows McTaggart when she says:

If the signing of the Declaration of Independence is later than the Lisbon earthquake, then the signing of the Declaration is always later

Manuscrito - Rev. Int. Fil. Campinas, v. 39, n. 4, pp. 117- 156, out.-dez. 2016. 
than the Lisbon Earthquake. The term "tenseless" refers to the fact that, given an inertial frame, B-relations between events do not change over time: once "earlier than" always "earlier than." (2007, p., p. 143)

In other words, Baker accepts the temporal principle ("TP" for short), according to which, if $x$ ever precedes $y$, then $\mathrm{x}$ always precedes $y$. At the preanalytic, common sense level, TP is undoubtedly true, and taken at face value, as Baker's commonsense approach urges us to do, TP implies that B-relations and the B-series facts they enter into exist in time, indeed, at every time. If, however, we take TP literally we must ask, what is the relation between the $\mathrm{B}$-series and time so that B-series facts can exist at every time? Indeed, what is the "time" at which each B-fact exists?

Perhaps by appealing to the A-series we can explain TP. More specifically, McTaggart maintains, and Baker agrees, events change from being future to present to past, "So, there are really many different A-series, not just one" (2010, p. 28). Since events ordered by the A-series are also ordered by the Bseries she could say that B-facts always exist by remaining the same or continue unchanged through many different A-series times. Unfortunately, this explanation of TP is unavailable to Baker, for if TP is true because the terms of B-facts have A-properties and change with respect to them then the $\mathrm{B}$-series cannot be more fundamental than the A -series. However, Baker claims "the B-series is more fundamental of the two orderings" (2007, p. 156). Indeed, she says:

My aim is to take the B-series as basic, but to jack up the A-series so that it too reveals an aspect of the nature of time. According to the BA theory of time, time has two irreducible aspects: one that depends on there being self-conscious entities (the aspect of the A-series, the ongoing now) and one that does not depend on self-conscious entities (the aspect of the B-series, simultaneity and succession). (2007, p. 149; emphasis added.)

Since the B-series does not depend on the A-series, but the A-series depends on the B-series ("The A-series is naturally taken as presupposing the B-series: Past events are those that occur earlier than those occurring now" (2007, pp. 151-152)), the former is more fundamental than the latter. Baker

Manuscrito - Rev. Int. Fil. Campinas, v. 39, n. 4, pp. 117-156, out.-dez. 2016. 
maintains B-relations can exist even if there are no A-properties, since they can exist apart from consciousness (upon which A-properties depend). So logically prior to consciousness, upon which A-series facts depend, there are B-series facts. "In the absence of self-conscious beings, events occur (tenselessly) at various times, and some events are (tenselessly) later than others. But there is no ongoing now" (2010, p. 32). Thus, tenseless B-series facts cannot always exist in virtue of existing at different A-series times. What then could be the ground of irreducible B-relational facts always existing, or existing at every time independently of the A-series?

If times are moments of absolute time, then B-facts could always exist by occupying every moment. In that case, however, the entire B-series would be one sempiternal totum simul, which is absurd. Moreover, if the unchanging temporal nature of B-relations and B-facts was grounded in the B-series occupying moments of time, then moments would form a B-series and the problem of grounding B-relations always existing would arise for the "times" at which B-series facts exist and so on ad infinitum. If times were understood relationally, then a B-series fact would always exist in virtue of being simultaneous with successive clock times, which themselves always exist and again, the problem of understanding TP remains.

Perhaps we could say that B-facts always exist, and so are temporal (meaning they exist in time) in virtue of coming into existence and then remaining in existence, but when does a $\mathrm{B}$-fact that $a$ is earlier than $b(a \mathrm{E} b)$ come into existence? Is it when $a$ comes into existence? If so, then $(a E b)$ is grounded in $a$ alone. When $b$ comes into existence? then if $a$ no longer exists, then the ground of $(a E b)$ is in $b$ alone. This view would ground Brelations in one of its terms: a strong notion of internal relations that is incompatible with the irreducible nature of time relations that are external relations. On this alternative B-relations are grounded in a relational property of one of the relation's terms: (Earlier than $b$ ) when $a$ exists, (Later than $a$ ) when $b$ exists. There is, however, nothing in addition to the relational properties, such as a relation between $a$ and $b$, that grounds the B-relational fact that $a$ is earlier than $b$. The problem is, how can $a$ have the relational property (earlier than $b$ ) when $b$ does not yet exist, and how can $b$ have the relational property (later than $a$ ) when $a$ no longer exists? On this gambit, there is nothing in the ontology of the world at $\mathrm{t}$ ' when $a$ exists, or $\mathrm{t}$ when $b$ exists, that could ground the existence of the B-fact that $(a \mathrm{E} \mathrm{b})$.

Manuscrito - Rev. Int. Fil. Campinas, v. 39, n. 4, pp. 117- 156, out.-der. 2016. 
There is a third alternative, namely, that first $a$ comes into existence and remains in existence, and then when $b$ comes into existence a acquires the relation of being earlier than to $b$. On this view when new temporal objects come into existence, new B-series facts come into existence, and then they "always" exist. The view that B-series facts come into existence when the later event occurs suggests a Growing-Universe view of time, according to which the past and present do, but the future does not exist. To see why consider that Baker defines coming into existence as follows:

To say that $\mathrm{x}$ comes into existence at $t$ is to say: ' $\mathrm{E} x t \&-\mathrm{B} t(t<t) \&$ E $\left.x t^{\prime}\right)^{\prime}$. If $x$ comes into existence at $t$, then $x$ did not exist before $t$. So, there is ontological novelty in the world.

If ( $a \mathrm{E} b$ ) comes into existence at time $t$ when $b$ comes into existence, then at $\mathrm{t}$, there does yet exist the B-fact that (b E c), since $c$ has not yet come into existence. As Baker puts it,

The ontology of the world at $\mathrm{t}=$ all abstract objects and all objects $\mathrm{x}$ such that Ext (2007, p. 230) ... We could go further and define the complete temporal ontology of the world at $t$ to include all the objects that came into existence at any time earlier than t. (2007, p. 230, fn 25)

Thus, objects that come into existence earlier than t, "exist" in the complete temporal ontology of the world at $t$, and thus, at $t$, the past exists. Baker's argues for the reality of the past in her critique of presentism:

If presentism . . . were correct, it is difficult to see how we could understand the difference between our meaningful talk about Plato and our meaningful talk about Pegasus. Pegasus never existed; Plato existed in the past. We speak meaningfully of Plato and we speak meaningfully of Pegasus; and it seems that our meaningful talk of Plato is grounded in Plato himself, whereas our meaningful talk of Pegasus is grounded in ancient stories" (2007, p. 155).

As new objects come into existence at a later time $t^{*}$, objects existing at $t$ and earlier acquire new temporal relations to those that become present at $t^{*}$ and these relations continue to exist from then on. ${ }^{1}$ Interestingly, Baker does

Manuscrito - Rev. Int. Fil. Campinas, v. 39, n. 4, pp. 117-156, out.-dez. 2016. 
not also say that the complete temporal ontology at $\mathrm{t}$ includes objects that come into existence later than $t$, thus further suggesting the non-existence of the future.

The following passages further support the view that the ontological inventory increases as objects come into existence by becoming present or now:

Ontology, as I have noted, is an inventory of what exists. Since contingent, concrete objects exist at some times, but not at other times, we are in no position to provide a complete ontology before the end of time. Nevertheless, modulo new developments, we can make an inventory as of now. (2007, p. 21; emphasis added.)

Clearly, this notion of the ontological inventory increasing/changing as different times become NOW, and objects and B-series facts come into existence, is an A-theoretic notion of absolute becoming that supports a growing universe view. Baker's commitment to A-theoretic becoming is further supported by her claim that "what is intuitively right about ... Presentism" is that "the ontology of the world [is] relativized to the present and changes over time" (2007, p. 231; emphasis added). Thus, what temporal objects and $\mathrm{B}$-series facts exist depends on what time is present. This is important point that provides further evidence for attributing to Baker a Growing Universe view of time.

Baker maintains that to understand the world that we actually encounter there must be ontological novelty, and thus the ontological inventory of the world-what exists--must be different at different times. What the world contains at any time $t$ differs from what it contains at any later time $t^{*}$ since the ontology of the temporal world is continually growing as new objects come into existence. On this reading, Baker conflates the common sense view that new things come into existence with the metaphysical view of the growing block universe, in which the future does not exist and the present is what has come into existence through absolute becoming.

To put the point differently, if, as Baker asserts, "we are in no position to provide a complete ontology before the end of time" (2007, p. 21), ontological novelty requires that the ontology of the world at $t$, does not include the contents of the world at any later time $t^{*}$. That is, at $t$, there does not exist a B-relation between an object that exists at $t$, and one that exists at any time

Manuscrito - Rev. Int. Fil. Campinas, v. 39, n. 4, pp. 117- 156, out.-dez. 2016. 
later than $t$, such as $t^{*}$. Thus, the future does not exist. For if, at $t$, there was a B-series fact that say the contents of $t$ precede the contents of $t^{*}$, then at $t$ there would be an answer to the what the world contains at $t^{*}$, and the future would exist. The complete temporal ontology of the world at $t$ would include all the objects that came into existence at any time earlier than $t$, and it would also include all the objects that come into existence at any time later than $t$. Since Baker explicitly asserts the first conjunct, but not the second, it follows that Baker is ontologically committed to the growing block, and thus that coming into existence is A-theoretic absolute becoming. Indeed, ontological novelty and diversity requires it. As she puts it, "The world changes ontologically over time as new objects like Socrates come into existence" (2007, p. 233). Since Baker includes "in ontology - the complete inventory of what exists" (2007, p. 4), if the world changes ontologically, then the "complete" inventory of what exists changes from time to time as new objects and B-series facts become present.

Although I have presented textual evidence for attributing to Baker the Growing Universe view and the corresponding interpretation of TP, there are also compelling reasons to deny it. First, Baker explicitly rejects the Growing Block Universe (and absolute becoming) since "As I said at the outset, I do not think that Presentism or Eternalism or the Growing Block Universe view is adequate" (2010, p. 34; emphasis added). Second, she distinguishes her view from the growing-universe view:

The mixed view may at first resemble a Growing-Universe View, but the "growth" is in the world; there is no room for "growth" in the complete ontology. And unlike the Growing-Universe Views, my view does not imply that objects that begin in the future do not exist, it only implies—which is surely right - that they do not exist now. (Baker, 2007, p. 231; emphasis added.)

In this passage Baker denies the Growing-Universe View by implying that objects that begin to exist in the future, or later than now, do exist, and that therefore, the complete temporal ontology of the world at $t$ does include all objects that come into exist later than $t$, including those contained at $t^{*}$. A view that follows from grounding TP in a B-series that always exists.

Third, a growing universe view of ontological novelty that requires a changing ontology through A-theoretic becoming is incompatible with Baker's

Manuscrito - Rev. Int. Fil. Campinas, v. 39, n. 4, pp. 117- 156, out.-dez. 2016. 
first main thesis, namely, the irreducibility of the B-series and the minddependence of the A-series, and therefore, with her BA-theory of time. To see what is involved recall that on Baker's BA view the A-series is minddependent, meaning that before there was consciousness, nothing was present, but there was still a B-series. We have seen, however, that on the growing universe view even before there is consciousness, and hence before there is a mind-dependent A-series, B-relational facts come into existence and thus are added to the ontological inventory as temporal objects become present. Since what temporal objects and B-facts exist depends on what time is NOW, it follows that the A-series does not depend on consciousness, as Baker maintains; but rather, the A-series depends on the mind-independent A-theoretic absolute becoming of temporal objects and B-series facts. For if temporal objects and B-relations didn't come into existence by becoming present mind-independently, then later states of consciousness could not exist, and therefore the world could not contain a mind-dependent A-series. Thus, the mind-dependent A-series (the A-series as we experience it) is not irreducible feature of temporal reality, but depends on ontological growth through absolute becoming.

The problem with reconciling Baker's comments about relativizing ontology to time, with her the BA view of time, can be stated differently. On Baker's view, an object, $o$, can come into existence at a time before there was consciousness or judgmental awareness. (2007, p. 152). However, when $o$ comes into existence (or first occurs), and so is part of the ontological inventory, $o$ is at that time present or NOW, and B-facts between $o$ and earlier objects come into existence. Thus, on Baker's view, an object can become present at a time before there was consciousness. Since Baker claims that "the A-series of past, present, and future is a product of our selfconsciousness" (207: 152), and $o$ can become present at a B-series time when there is no consciousness, it follows that Baker's commitment to a basic, irreducible mind-dependent A-series is incompatible with her A-theoretic view of coming into existence. For the same reason, the B-series as an irreducible temporal series is also undermined. Since, B-series facts come into existence as the later terms of B-relations become present, it follows that Bfacts, and the terms of B-relations also depend on the more fundamental notion of absolute becoming, and so are not irreducible.

Manuscrito - Rev. Int. Fil. Campinas, v. 39, n. 4, pp. 117- 156, out.-der. 2016. 
For these reasons it is clear that Baker must reject the growing universe view according to which the future does not exist, and objects and B-relations come into existence through A-theoretic becoming present. However, her rejection of the growing universe and her commitment to TP undermines her second main conclusion to which I shall turn to next.

\section{Ontological Diversity, Novelty and the Unchanging Domain}

Baker states her second main conclusion in the following passage:

There is no conflict between the commonsense view that the world exhibits ontological novelty and the metaphysical view that the domain of the unrestricted existential quantifier is nontemporal. The world changes ontologically over time, as new objects like Socrates and new kinds like dinosaurs come into existence. Nevertheless, the domain of the unrestricted existential quantifier is not subject to change (because it is not temporal at all). (2010, p. 42)

Baker presents a useful summary of her thesis: "My aim is to show that although the Domain is not subject to change (as Eternalists hold), the world is ontologically different at different times (as Presentists hold)." (2010, p. 35)

To see why is unsuccessful in accomplishing her aim let's take a closer look at what it means to be in the Domain.

To be in the Domain is to be within the scope of the logician's ' $\exists$ '. What does the Domain include? The Domain includes everything; it is the complete ontology. Since it is the complete ontology, nothing can be added to the Domain and nothing can be taken away from it. "Existential quantification does not entail that a temporal object exists at the time that it is quantified over; it entails, rather, that it exists at some time or other" (2007, p. 230; emphasis added).

Suppose we agree with Baker in maintaining that TP is true because Bseries facts are unchanging (tenseless) and therefore permanent; they always exist. All objects earlier than $\mathrm{t}$, and all objects later than $\mathrm{t}$ exist at those earlier and later times. On this view, neither temporal objects nor B-series facts come into existence though absolute becoming. Then, since Baker maintains

Manuscrito - Rev. Int. Fil. Campinas, v. 39, n. 4, pp. 117-156, out.-dez. 2016. 
that an object existing at a time implies that the object is a temporal object, and being a temporal object is sufficient for being in the Domain, it follows that if at any time $t$, there exists a later time $t^{*}$, such that $x$ exists or occurs (tenselessly) at $\mathrm{t}^{*}$ and there exists at an earlier time $\mathrm{t}^{\prime}$ such that $y$ exists at $\mathrm{t}^{\prime}$, then $x$ and $y$ would be included in and exist simpliciter in the Domain. Furthermore, since the entire B-series involves relations between earlier and later temporal objects, it follows that all temporal objects in the B-series exist (tenselessly) at the time they do regardless of what time it is. That is, objects exist at the time they do permanently or at every time. Thus, the ontology of the world is not different at different times, and consequently, although it is true that the Domain is unchanging because it is non temporal, it is not true that the world exhibits ontological diversity or novelty as the mixed view requires, and for that reason Baker's second main conclusion is false.

Baker maintains that the complete ontology of the world does not exist until the end of time. This is because the Domain is time indexed; what exists in the world depends on what time it is, and for that reason there is ontological novelty and diversity. However, if a B-series fact is unchanging then it always exists. If it always exists, then at each time it is a $\mathrm{B}$-fact that the terms of the relation exist at their respective times. For example, at any time $\mathrm{t}, a$ exists at $\mathrm{t} 1$ and $b$ exists at $\mathrm{t} 2$ and $a$ exists at $\mathrm{t} 1$ is earlier than $b$ exists at $\mathrm{t} 2$, similarly for all objects that are terms of the B-series. Since "Socrates is in the Domain in virtue of the fact that there is a time at which he exists" (Baker 2007, p. 229; emphasis added). Since the B-series always exists, Socrates existing (tenselessly) in $399 \mathrm{BCE}$ always exists as a term in the B-series. Since the same is true for every B-series term, there is no difference between the complete temporal ontology of the world at any time $t$, and any later or earlier time. Thus, we need not wait until the end of time to get the complete ontology, nor is there any difference between the unchanging non temporal Domain, and the ontology of the world at any time.

I conclude that if A-theoretic becoming is not introduced into her ontology, then new objects do not come into existence and hence there is no ontological novelty. For if coming into existence is understood in terms of an object not existing at a time earlier than the first time it exists, then there is not and could not be coming into existence. Since Ext (x exists at $t$ ), always exists, (as it must since it is term of an always existing B-series fact), Ext is at a time $\mathrm{t}$ ' before $\mathrm{t}$, so $\mathrm{x}$ cannot come into existence at $\mathrm{t}$.

Manuscrito - Rev. Int. Fil. Campinas, v. 39, n. 4, pp. 117-156, out.-der. 2016. 
To sum up, given TP and the denial of the growing block, Baker's mixed view requires that the Domain - the "complete" ontological inventory - is unchanging because it is not temporal at all, but also that the Domain - the ontological inventory as of NOW - is changing to account for ontological novelty and so is not complete until the end of time. Thus, without absolute becoming, and given that the B-series always exists, the Domain of the unrestricted quantifier is indeed unchanging (and non-temporal), but there is no ground for claiming that the world changes ontologically as new objects become present. On the other hand, if the ontology of the world changes depending on what objects come into existence NOW, then there is growth and ontological novelty. However, in that case, the temporal B-series (as the whole history of the universe) is not unchanging since it is continually being added to, and the complete Domain is not non-temporal since it comes into existence at the end of time.

Thus, Baker faces a dilemma. If she accepts the growing universe and TP (suitably modified to allow for growth in B-series facts), then her BA theory of time is undermined, and her second main conclusion is false as well since the Domain is temporal and changing, and not non temporal and unchanging as on her view it is required to be. If she rejects the growing block, but accepts TP then her second conclusion is undermined because the world does not change ontologically over time, and ontological novelty is lost.

It would appear then that it is a mistake to use McTaggart's notion of the $\mathrm{B}$-series as one aspect of the framework for the BA theory of time, since it is unclear how to make sense of B-series facts "always existing" without insurmountable problems. Could Baker avoid these unattractive consequences by distinguish the commonsense acceptance of PT from the ontological analysis of it, and by employing the R-theoretic notions of Rrelations and R-series facts? I shall pursue that question after a further discussion of the R-theory.

\section{The R-theory, R-Relations and R-series facts}

Suppose that temporal relations such as earlier than and temporal relational facts such as $(a \mathrm{E} b)$ are timeless in the sense that they do not exist in time at all. Since this would go against Baker's McTaggartian B-theoretic claim that

Manuscrito - Rev. Int. Fil. Campinas, v. 39, n. 4, pp. 117-156, out.-dez. 2016. 
B-relations and B-series facts are temporal because they always exist, let us refer instead to the R-theory whose R-relations and R-series facts are timeless. Since the R-theory is a purely relational theory of time, to say that R-relations and $\mathrm{R}$-facts are timeless is to say that they are not terms of time relations. So the first difference between the $\mathrm{B}$-series and the $\mathrm{R}$-series is that the $\mathrm{B}$-series is temporal, whereas the R-series is timeless.

How, then, one may ask, can temporal R-relations and temporal R-facts be timeless? Is that not a contradiction in terms? Baker says something that can help us shed light on the answer to these questions:

It is important not to confuse the tenselessness of the B-series with timelessness. The mathematical relation 'greater than' is timeless, but 'earlier than' is a paradigmatic temporal relation. (2007, p. 145)

In one respect I would disagree. On the R-theory, 'earlier than' just as the mathematical relation of 'greater than' is timeless since they are both relational universals. Of course, if what Baker is getting at is that the terms of the of the mathematical relation 'greater than' are timeless, whereas the terms of 'earlier than' are in time or temporal, then what she says is true. There is, however, another way of understanding the distinction between "timeless" mathematic relations and "temporal" R-relations, although not Baker's, that is useful for our purposes. In a second sense, 'greater than' is timeless in being is a static (nontransient) relation that generates an order, but is not dynamic, since it cannot account for the sense in which we experience time as passing when we hear sounds (notes) rapidly succeeding each other on a piano or looking at a flickering flame. What is paradigmatic about temporal R-relations is that they are the ground of our experience of the passage or the flow of successively existing events. To understand our experience of passage as grounded in R-relations is to understand temporal R-relations as dynamic and not static, and there being an intrinsic direction between temporal objects that 'greater than' among numbers, or 'to the left of among spatial objects does not have. This sense of "temporal" is compatible with R-relations being both temporal (dynamic) and timeless (do not exist in time), and R-facts being unchanging.

Thus, we must distinguish two senses of "temporal" and "timeless." In one sense an entity is temporal ${ }_{1}$ if it exists in time and timeless ${ }_{1}$ if it exists outside of time. In a second sense, an entity is temporal ${ }_{2}$ if it dynamic

Manuscrito - Rev. Int. Fil. Campinas, v. 39, n. 4, pp. 117-156, out.-der. 2016. 
(involves passage or transition) and timeless ${ }_{2}$ if it is static. Thus, unlike the $\mathrm{B}$-series, for the R-theorist the tenselessness of the R-series does not imply that its generating relation or its terms, nor R-series facts themselves, always exist. On the R-theory, to be "TENSEless" means that neither R-facts, nor R-relations nor the terms of R-relations, are TENSED, that is, exemplify Aproperties. The R-theory being a TENSEless theory of time is compatible with the timeless ${ }_{1} \mathrm{R}$-relation that generates the $\mathrm{R}$-series being temporal ${ }_{2}$ and the temporal $2 \mathrm{R}$-series fact that contains a temporal 2 relation being timeless $s_{1}$. To suppose that the R-relation 'earlier than' is a static (timeless 2 ), temporal 1 relation and that the $\mathrm{R}$-series is a temporal ${ }_{1}$ fact that always exists is to radically distort, indeed contradict, the R-theory and it is just such a distortion that occurs when one construes Russell's R-series as McTaggart's B-series. The $\mathrm{R}$-series is unchanging because it is timeless ${ }_{1}$, not because it remains the same throughout all time.

Furthermore, the R-theory is compatible with the common sense view that temporal objects come into existence and cease to exist. $X$ comes into existence at $\mathrm{t}$ if it does not exist at any time $\mathrm{t}^{\prime}$ earlier than the first time $\mathrm{t}$ at which it is located at, and it ceases to exist if it does not exist at a time $t^{*}$ later than the last time it is located. Here "existence" is TENSEless, so that to say that $\mathrm{x}$ TENSElessly exist at $\mathrm{t}$ means that $\mathrm{x}$ exists at $\mathrm{t}$ without any of the TENSED properties pastness, presentness or futurity, and a fortiori, without having to come into existence at some time which is present or NOW. The timeless 1 existence of R-facts, and the TENSEless existence of $x$ at $t$ does not imply that x "pre-exists" or "already exists" at any time t' earlier than t, or that $x$ is an eternal object that exists outside of time altogether, as Baker suggests eternalism is committed. ${ }^{2}$ (Cf. 2007, p. 228; cf. p. 229.) Again these criticisms do not apply to the R-theory unless one confuses Russell's R-series with Mc'Taggart's B-series.

With this background let's return to the question: Could Baker explain the temporal principle (TP) by appealing to TENSEless, but temporal 2 relations that are unchanging or "always" existing in virtue of being constituents of timeless ${ }_{1}, \mathrm{R}$-series facts? Prima facie, the answer is "no." For if (a E b) exists as timeless $s_{1}$, then it cannot be claimed to always exist, that is, existence at all times, for then it would be temporal. Since, however, Baker does claim that "If the signing of the Declaration is later than the Lisbon earthquake, then the signing of the Declaration of Independence is always later than the Lisbon

Manuscrito - Rev. Int. Fil. Campinas, v. 39, n. 4, pp. 117-156, out.-dez. 2016. 
earthquake" (2007, p. 143; emphasis added), her view contradicts the claim that R-facts exist as timeless 1 . However, by adopting the first methodological stance and distinguish common sense and ontology as R-theorists do, maybe Baker could appeal to timeless1 R-facts, and ground the "unchanging" and "permanent" character of temporal relations in terms of timeless 1 R-facts, rather than temporal ${ }_{1} \mathrm{~B}$-facts, and the difficulties of taking a literal ontological interpretation of TP may be avoided.

Unfortunately, I don't think that gambit is available to Baker regardless of whether she adopts a growing universe view or rejects it. If she adopts ontological growth through absolute becoming, timeless 1 R-series facts collapse into temporal $l_{1}$ existents. If at time $t$ or earlier neither $a$ nor $b$ exist, since neither have come into existence through A-theoretic becoming, then they cannot be constituents of the fact $(\mathrm{a} E \mathrm{~b})$. Since an R-fact cannot exist unless both its relata exist, how could a timeless ${ }_{1} \mathrm{R}$-series fact contain what "a" and "b" stands for when what they stand for is at sometimes literally nothing? Thus, at a time before $a$ and $b$ exist, the R-fact that $(a \mathrm{E} b)$ cannot exist, and then when $a$ and $b$ come into existence the fact can exist. But this is against the very notion of a timeless ${ }_{1}$ fact. For, if a fact must change in this way then it is in an obvious sense in time and therefore, not timeless 1 but itself a temporal 1 existent.

To put the same point in a slightly differently way, the growing block view assumes that existence involves temporal objects becoming present: since what exists depends on what time is NOW, the future does not exist as part of the ontological inventory, even as what is later than now. However, since $\mathrm{R}$-facts may literally contain existents regardless of when they those existents (TENSElessly) occur, and R-facts cannot be without reference to them, it follows on Baker's view of becoming, R-facts cannot be until the time when the temporal objects they contain have come into existence. Thus, R-facts cannot come into existence until the later existent in it becomes present. In that case, an R-fact is no longer the timeless 1 entity that the R-theory intends it to be, but rather itself a temporal ${ }_{1} \mathrm{~B}$-fact. We may conclude that Baker must either reject the growing universe account of time and existence (including her A-theoretic account of coming into existence), or deny that the temporal principle can be understood in terms of timeless 1 R-facts.

Suppose that the growing universe is rejected. If TP is interpreted as on the R-theory, so that (a E b) is unchanging and "always" the case because it

Manuscrito - Rev. Int. Fil. Campinas, v. 39, n. 4, pp. 117-156, out.-der. 2016. 
is timeless 1 , then we can agree that an object comes into existence so long as there is no earlier time at which it exists. The Domain is timeless, but the ontology of the temporal world is also timeless, for the conjunction of Rseries facts that constitute the history of the world does not exist in time, although temporal objects and temporal 2 relations, and change do exist in the world. On the R-theory the ontology of the temporal world does not change over time as Baker's mixed view requires, since the temporal world does not exist in time, but rather time, that is temporal 2 relations between temporal objects and change exist in it.

In other words, if we have the R-series, which "always exists" in the sense of being timeless, then there is coming into existence, yet there is no ontological diversity in the sense Baker requires it, since the ontology of the world is not different at different times. Admittedly, the events that occur at one clock time are different from those that occur at another, but it does not follow that the world as a whole is different at each of those times. The world as a whole does not exist in time, and the notion of coming into existence absolutely as the world "grows" is incompatible with the R-theory. From the R-theorist perspective, since the ontology of the world contains time, i.e., the $\mathrm{R}$-series, which is timeless, it makes no sense to say that it changes at different times. Things change in time, but the world, which contains things, does not change.

In an early defense of Russell's view of time against Broad's growing universe view, R. M. Blake expresses a position that I have can be called Russellian and to which I owe much. He says:

There is certainly a unique character about time which cannot be reduced to anything else. Time is filled with "events, and events are bappenings," things that "come to pass," that succeed one another in a fixed direction of earlier and later. This feature of time is revealed to us in our immediate experience of duration and the passage of events. But we may be equally certain that, however much of succession there may be in events, every event has in the order of succession just the place that it has and none other. The order as a whole, however much it may be an order of change and of succession, must in a sense be "static," for it must be true that it is what it is. Let fluidity be never so fluid, the fact that it is so remains unaltered. These are simply the necessities of logic. (Blake, 1924: 434-435; emphasis added.)

Manuscrito - Rev. Int. Fil. Campinas, v. 39, n. 4, pp. 117-156, out.-dez. 2016. 
Blake is attempting to reconcile the fundamental features of our experience of time and its true nature; that time has a unique and irreducible character that distinguishes it from space that is revealed to us through our experience of the succession of events, on the one hand, with the notion that time forms an ordered series of terms in which every item has just the place it has and no other, and that the whole conjunction of facts is unchanging, on the other. I am suggesting that to understand these two aspects of time one must recognize that time contains timeless 1 yet dynamic relations and temporal 2 yet eternal (timeless 1 ) facts. To countenance R-facts in addition to R-relations is crucial to providing a ground for the unchanging character of time as a whole and the dynamic nature of time within it.

By contrast, Baker's view attempts to incorporate what she takes to be the intuitive or common sense aspects of the Growing Universe View (the world grows as new objects come into existence), Presentism (the ontology of the world is relative to, and changes over time) and Eternalism (the Domain of the unrestricted existential quantifier is fixed; it is not subject to change) into the ontology of the $\mathrm{BA}$ view of time (B-series and $\mathrm{A}$-series are basic and irreducible) and her bimodal or mixed view of time and existence, according to which there is ontological novelty in the world as new entities come into existence, but the Domain is unchanging. I have shown, however, that regardless of how she interprets TP, whether in terms of Mc'Taggart's temporal $_{1} \mathrm{~B}$-series or in terms of the timeless ${ }_{1}$ (yet temporal 2 ) R-series, the result is that neither the $\mathrm{BA}$ view of temporal reality nor the mixed view of time is consistent.

In the final section of this paper I shall consider Baker's arguments against the B-series and Eternalism as alone constituting time, and argue that they do not apply to the R-theory, that is, for that reason preferable.

8. Baker's Criticism of Eternalism

It is, I believe, important to note that McTaggart categorizes Russell's Bseries as a permanent series since B-relations, their terms, and the B-facts they enter into always exist. Thus, when McTaggart argues that B-series alone cannot exist as a temporal series he is beginning with an interpretation of Russell's account of temporal relations that no R-theorists would accept. Similarly, when Baker says that her understanding of time "begins with McTaggart's framework of the A-series and the B-series-the framework that underlies both presentism and eternalism" (2010, p. 27), she is buying into

Manuscrito - Rev. Int. Fil. Campinas, v. 39, n. 4, pp. 117-156, out.-der. 2016. 
what is a decidedly anti-Russellian view of temporal relations. Given Baker's McTaggartian understanding of the B-series that she embeds into common sense, her arguments against eternalism, and the B-series alone constituting time are plausible, but I will argue do not undermine the R-theoretic framework, that shares with new and old TENSEless theories of time the negative thesis that all A-theoretic analyses, such as presentism, the growing universe, and the moving now theories of time are mistaken.

One argument McTaggart gives against Russell is that the B-series without the A-series does not involve events coming into existence and ceasing to exist:

If $\mathrm{N}$ is ever earlier than $\mathrm{O}$ and later than $\mathrm{M}$, it will always be, and has always been, earlier than $\mathrm{O}$ and later than $\mathrm{M}$, since the relations of earlier and later are permanent. $\mathrm{N}$ will thus always be in a B series. And as, by our present hypothesis, a B series by itself constitutes time, $\mathrm{N}$ will always have a position in a time-series, and always has had one. That is, it always has been an event, and always will be one, and cannot begin or cease to be an event. (McTaggart 1921, 45-46)

This conception of the B-series (without the assumption of the A-series) is virtually isomorphic with Baker's characterization of the B-series that she claims is the basis for Eternalism. For if, as we have seen, Baker says, "The term 'tenseless' refers to the fact that B-relations between events do not change over time: once "earlier than," always "earlier than" (2010, p. 28), it follows that the tenseless existence of the B-series, and the tenseless existence of events and temporal objects at clock times, always exist. It is not surprising, therefore, that Baker interprets eternalism as committed to just that. She says:

On the eternalist view (as I understand it) the ontology of the world at any time is just the collection of objects that make up the Domain.... Eternalists seem to construe 'being at the Domain' to imply the following: if $\mathrm{x}$ is in the Domain, then there is no time at which $\mathrm{x}$ is not in the Domain; and hence, $\mathrm{x}$ is in the Domain at all times. And hence, further, if $x$ ever exists, there is no time that $x$ fails to exist. (2007, p. 40; emphasis added.)

Furthermore, Baker is correct in asserting that "If this is what eternalists hold, then eternalists (unlike mixed viewers) suppose that objects do not

Manuscrito - Rev. Int. Fil. Campinas, v. 39, n. 4, pp. 117- 156, out.-dez. 2016. 
come into existence at times" (2010, p. 40). Indeed, if every term of the Bseries exists at all times, then the B-series is not a temporal series at all, but a totum simul. In that case, the relations between these terms are not temporal relations, but are static and nontransient as Baker (2010, p. 34) claims them to be. Finally, although Baker denies that eternalism implies (deterministic) fatalism (2007, p.145), she quotes a passage from Sider that, together with passages just sighted, and the one immediately following, strongly suggest that the Bseries and thus eternalism does imply (logical) fatalism. "When Sider says that "the world comes "ready-made" with a single domain D of objects: the class of all objects there are' (Sider 2001, xxii) it sounds as if he is taking the Domain to constrain what exists at particular times" (Baker 2007, p. 232). ${ }^{3}$

Whatever the accuracy of this understanding of the B-series and eternalism, stemming from McTaggart's interpretation of Russell, it does not correctly characterize the R-theory. Unlike Baker, the R-theorist distinguishes between the common sense temporal principle (TP) and its ontological analysis. For the R-theorist the unchanging (TENSEless) fact that (a E b) and TENSEless existence of Socrates in 399 BCE, does not imply that the Rseries fact or Socrates occurrence in 399 BCE exist at every time. Socrates exists in time in virtue of being a term of a R-relation, and his existing at a specific time concerns the network of R-relations he stands in. The R-series "always exists" in virtue of being outside of time, not in virtue of existing at every time, and since the timeless 1 existence of the R-series does not imply either the timeless or sempiternal existence of its terms, if $\mathrm{x}$ ever exists as a term of an R-relation it does not follow that it always or at every time, exist as a term in the R-series. Hence it does not follow that the terms of Rrelations do not come into or cease to exist.

With this background we can turn to Baker's arguments against the Bseries, the B-theory and eternalism. Before I begin there are two caveats. I shall put aside any objections that Sider or any other defender of the B-theory as Baker understands it would give in response to her criticisms, and will only be concerned with whether or not her criticisms apply to the R-theory. Baker never refers to or mentions the R-theory and it plays no role in her view of

\footnotetext{
${ }^{3}$ In Oaklander (1998) I argue that the B-theory (as I then understood it, which is pretty much as I now understand the R-theory), can avoid the charge of logical fatalism and other arguments that the $\mathrm{B} / \mathrm{R}$ theory robs us of our freedom.
}

Manuscrito - Rev. Int. Fil. Campinas, v. 39, n. 4, pp. 117- 156, out.-der. 2016. 
time. Therefore, her objections to the B-series alone constituting time were not intended to apply to the R-theory.

Baker gives three main arguments for the claim the B-series is not sufficient to understand all temporal facts. The first is that the A-series is indispensable to time since "The B-series without the A-series leaves out the paradigmatic temporal properties of past, present, and future altogether" (2010, p. 30). In referring to "paradigmatic" A-properties, Baker seems to be arguing that since we uncontroversially characterize the world in terms of past, present and future, it follows that there are A-properties. Or, in terms familiar to us from our discussion of methodology and ontology, she takes the indisputable truth of common sense statements such as "The earth has existed for many years past" or "The meeting starts now," as tantamount to an ontological commitment to A-properties. Thus, to deny A-properties is to deny what are uncontroversial, commonsensical truths, which is absurd. Clearly, Baker's first argument assumes the first methodological stance regarding common sense and ontology, but from the R-theorist, the "certainty" of common sense temporal proposition must be distinguished from the ontological analysis or fact that is it's ground. Indeed, the problems surrounding Baker's philosophy of time, which is founded on attempting to construct an ontology that treats ordinary life, language and thought as embodying irreducible realities, undermines her claim that the B-series is inadequate because the A-series is indispensable since it rests on that assumption.

While the first argument does not argue for the indispensability of the Aseries, but assumes it, the second argument is that,

There are many temporal facts that the B-series without the A-series cannot recognize-e.g., that this is the twenty-first century or that social services in the US used to be more secure than they are now. The B-series offers no way for the doctor to tell you that you have less than a year to live, or for you to assure the school board that the Earth is millions of years old now. (And your having less than a year to live and the Earth's being millions of years old now are by no means "subjective" or a product of psychological attitudes). (2007, p. 146)

To say that these judgments are "by no means 'subjective' or a product of psychological attitudes" is either true, but irrelevant or question begging or

Manuscrito - Rev. Int. Fil. Campinas, v. 39, n. 4, pp. 117-156, out.-dez. 2016. 
false. It is true that the duration between that the date that the doctor informs you of your impending death and the date you die is less than a year, is by no means subjective. However, it does not follow from that, nor is it true, on the R-theory, that the temporal fact that doctor wishes to convey cannot be conveyed by and are grounded upon R-series facts alone that include psychological facts.

On the psychological analysis of the tenses, what the doctor means when she asserts that "You have less than a year to live" is that your passing away occurs less than one year after this, where this is some experience or some perceptual object she is conscious of simultaneously with making the utterance. What the hearer understands by the doctor's utterance is that her death is less than one year later than her consciousness of hearing this utterance of the speaker. There are no further A-series facts needed to account for or convey the fact in question, nor does the appeal to "this utterance" or "this perception" reintroduce the ongoing now. ${ }^{4}$

Baker's third argument for the indispensability of the A-series is that the B-series alone cannot account for many ordinary kinds of phenomena, e.g. Regret, emotional attitudes making and executing plans and the like. As she puts it:

The A-series is required for the occurrence of many kinds of ordinary phenomena-for making and executing plans, for regret, for making sense of ourselves and the world. A-series facts are explananda that need A-series explanations. Why are you so sad today? Because someone close to you died last night. (Being sad at t because someone died at $\mathrm{t}-1$ is not the same at all as being sad today; being sad today because someone died last night has the sting of grief that the tenseless fact of being sad at $\mathrm{t}$ because someone died at $\mathrm{t}-1$ just does not have.) So, I conclude that we cannot just eliminate the A-series in favor of the B-series. (2010, p. 30)

When Baker says that "A-series facts are explananda need

\footnotetext{
${ }^{4}$ For a discussion of the argument that the use of the word "this" brings back tense and hence the A-series into the analysis see, Broad (1928), Gale (1962), Smart (1963) and Orilia and Oaklander (2013).
}

Manuscrito - Rev. Int. Fil. Campinas, v. 39, n. 4, pp. 117- 156, out.-dez. 2016. 
A-series explanations" (2010, p.30), she is identifying an indisputable common sense fact "I am sad today" with an ontological A-series fact, but even if she is not, it is clear that her critique assumes a date analysis of tense. On the date-analysis the sentence "I am sad today" uttered at $\mathrm{t} 1$ is true if and only if "My sadness occurs at $\mathrm{t} 1$ " and although it is true that the date analysis cannot account for the cognitive significance of certain psychological attitudes and emotions, there is also the psychological analysis which is not necessarily even in part A-theoretic, that can.

From the perspective of the R-theory, which adopts a psychological analysis, what explains why person is sad today is a belief to the effect that this memory of my friend dying on November 19, 2016 is one day later than her death. Similarly, a sufficient condition for Tom's getting to a 1 p.m. meeting on time could be his believing that this perception of $s$ is roughly simultaneous with the clock's striking 1 p.m., where $s$ is Tom's mental token of "the clock strikes 1 p.m." (which surfaces to his mind upon looking at the clock). Or, a sufficient condition for Tom's being relieved that he will never have to give another lecture again could be his believing that this thought of $s$ is later than his giving his very last lecture, where $s$ is his mental token of "finally I gave my last lecture." In sum, although it might seem at first glance that the A-series is needed to allow us to react to dangers, keep our appointments or have emotional responses one can see that combining the R-theory with psychological approach can also accomplish that task.

A further criticism Baker raises against eternalism is that:

Eternalism has no place for an ongoing now in its account of reality. Nor does it have the resources to show how temporal reality, conceived of wholly in terms of the B-series, could give rise to the appearance of an ongoing now, as opposed to successions of simultaneous events. If all there is to time is the B-series, how could our lives be so bound up with the passage of time? (2007, p. 233)

Admittedly, on the R-theory there is no ongoing now, interpreted as either as the Growing Universe view, presentism, according to which new temporal objects come into existence through absolute becoming, or as the traditional A-series theorist would think of it, in terms the property of presentness moving from one time/event/object to another. However, if Baker takes one of

Manuscrito - Rev. Int. Fil. Campinas, v. 39, n. 4, pp. 117-156, out.-dez. 2016. 
those interpretations or any other A-theoretic analysis of our appearance of an ongoing now to be a common sense fact that is irreducibly real then from the R-theoretic perspective she is assuming an erroneous conception of the relation between common sense and ontology.

Moreover, even if that conflation is not made, the R-theory does have the resources to show explain our experience of an ongoing now or moving present, since an R-theorist need not reduce our experience of passage to that of a successions of simultaneous events. Recall that for Russell we can be aware of a duration in perception, since a temporal relation between two notes $(\mathrm{C}$ and $\mathrm{D})$ can be consciously perceived as present, and another conscious perception of and successive notes (D and E) can be experienced as present. In these cases, D is later I the first perception and earlier in the second, and in that way we are have successive conscious perceptions of an ongoing now. Each perception involves a dynamic aspect, namely a temporal 2 relation between two consciously experienced notes, and then a subsequent perception between two notes the first of which overlaps with the later object of the earlier perception. Hence we experience the moving present, without A-series properties. This seems to be Russell's idea in the following passage: Suppose, for example, the sounds A, B, C, D, E occur in succession, and three of them can be experienced together. Then $\mathrm{C}$ will belong to a total experience containing $\mathrm{A}, \mathrm{B}, \mathrm{C}$, to one containing $\mathrm{B}, \mathrm{C}, \mathrm{D}$, and to one containing $\mathrm{C}, \mathrm{D}, \mathrm{E}$. in this way, in spite of the fact that the specious present lasts for a certain length of time, experience permits us to assign the temporal position of an object much more accurately than merely within one specious present. In the above instance, $\mathrm{C}$ is at the end of the specious present of $A, B, C$ in the middle of that of B, C, D, and at the beginning of that of C, D, E. (Russell 1915, p. 178)

Thus, on the R-theory, the successive perceptions of overlapping durational contents give rise to the experience of the moving present or an ongoing now. The R-theory also has the resources to account for our experience of the passage of time or temporal becoming that is the change events undergo when we experience of them moving from the future to the present and into the past, as I have argued elsewhere. ${ }^{5}$

${ }^{5}$ Oaklander (2015).

Manuscrito - Rev. Int. Fil. Campinas, v. 39, n. 4, pp. 117- 156, out.-dez. 2016. 
There are other arguments, in the neighborhood of those Baker gives, for why the A-series is required to understand what we are thinking and intend to express when we say, for example, "I wish it were now some other time" and I have dealt with many of them elsewhere. ${ }^{6}$ Suffice it to say that if we distinguish common sense and ontology on the one hand, and avoid conflating the Russellian view with McTaggart's ontological analysis of the Bseries or Baker's A-theoretic analysis of TP on the other, then the R-theory is preferable to both eternalism (as Baker understands it) and to the BA-theory of time.

\section{References}

BAKer, Lynne RudDer. "Temporal Reality," in J. K. Campbell, M. O’Rourke and H. S. Silverstein (eds.), (2010), pp. 27-47. The Metaphysics of Everyday Life. Cambridge: University Press, 2007. "On the Mind-Dependence of Temporal Becoming". Philosophy and Phenomenological Research, 39, pp. 341-357, 1979.

"Temporal Becoming: The Argument from Physics". Philosophical Forum, 6, pp. 218-236, 1974-75.

Bardon, Adrian (ed.), The Future of the Philosophy of Time. New York: Routledge, 2012.

BLAKE, R. M. “On Mr. Broad's Theory of Time”. Mind, 34, pp. 418-35, 1925. Bonino, G.; Jesson, G., CumpA, J. Defending Realism: Ontological and Epistemological Investigations. Boston: De Gruyter, 2014.

BroAd, C. D. "Time and Change". Proceedings of the Aristotelian Society, Supplementary Vol. 8, pp. 175-88, 1928.

BROAD, C. D. "Time," in J. Hastings et al., eds., Encyclopedia of Religion and Ethics, Vol. 12. Edinburgh and New York: T. \& T. Clark and Scribners, 1921. (http://www.ditext.com/broad/time/timeframe.html) Repr. in Oaklander (2008), Vol. I, pp. 143--173.

Campbell, J. K., O’Rourke, M., Silverstein, H.S. Time and Identity. Cambridge, Mass: MIT Press, 2010.

${ }^{6}$ See, Oaklander (2008) and (2004, chapters 15-22).

Manuscrito - Rev. Int. Fil. Campinas, v. 39, n. 4, pp. 117-156, out.-dez. 2016. 
DAinton, B. 'Time and Temporal Experience', in A. Bardon (ed.) (2012), pp.123-148.

Dolev, Y. Time and Realism: Metaphysical and Antimetaphysical Perspectives. Cambridge, MA: MIT Press, 2007.

Friedman, Eugene AND SELlars, Wilfrid. (eds.) Basic Issues in the Philosophy of Time. La Salle, IL: Open Court, 1971.

Gale, R. "Tensed Statements". Philosophical Quarterly, 12, 1962. Repr. in Oaklander (2008), Vol. I, pp. 210-217.

GRÜNBAUM, A. "The Meaning of Time". In Eugene Friedman and Wilfrid Sellars (eds.) (1971), pp. 193-228.

HOY, RONALD C. and L. NATHAN OAKLANDER. (eds.) Metaphysics: Classic and Contemporary Readings. Belmont, Ca: Thomson Wadsworth, 2005.

KAPITAN, T. "Indexicality and Self-Awareness". In U. Kriegel and K. Williford, (eds.) (2006), pp. 397-408.

Kriegel, U. and WiLliford, K. Consciousness and Self-Reference, Cambridge, Mass.: MIT Press, 2006.

LE PoIdevin, Robin. (ed.), Questions of Time and Tense. Oxford: Clarendon Press, 1998.

MARSH, ROBERT C. (ed.) Logic and Knowledge: Essays 1901-1950. London and NY: Routledge, 2001.

MCTAggart, John M. E. and C.D. BroAD. (eds.) The Nature of Existence, vol. II. Cambridge University Press, 1921-1927.

MCTAggarT, John M. E. "Time”. (1921). Repr. in Ronald C. Hoy and L. Nathan Oaklander. (eds.) (2005), pp.44-55. The unreality of time. Mind 17, pp. 457-84, 1908.

MOORE, G. E. "Symposium: Is There "Knowledge by Acquaintance". Aristotelian Soc. Supp. 2, pp. 185-205, 1919.

OAKLANDER, L. N. "Temporal Phenomena, Ontology and the R-theory". Metaphysica: International Journal of Ontology, pp. 253-269, 2015.

"Temporal Realism and the R-theory," In Guido Bonino, Greg Jesson, Javier Cumpa (eds.) (2014a), pp.123-139.

Debates in the Metaphysics of Time. Bloomsbury: New York and London, 2014b.

"Dolev's Anti-Metaphysical Realism: A Critique". In L. Nathan Oaklander (ed.) (2014c), pp. 4-29

Manuscrito - Rev. Int. Fil. Campinas, v. 39, n. 4, pp. 117- 156, out.-dez. 2016. 
"A-, B- and R-Theories of Time: A Debate". In Adrian Bardon (ed.) (2012), pp. 1-24.

"Be Careful What You Wish For: A Reply to Craig". Philosophy and Phenomenological Research, vol. 76, no. 1, 2008. The Ontology of Time. Amherst, NY: Prometheus Books, 2004. The Philosophy of Time: Critical Concepts in Philosophy. London and New York: Routledge, 2008.

"Freedom and the New Theory of Time". In Robin Le Poidevin (ed.), Questions of Time and Tense. (1998) Repr. in L. Nathan Oaklander. (ed.) (2008), vol. 3, pp.250-270

ORILIA, F., OAKLANDER, L.N. "Do we really need a new B-theory of time?" Topoi, (2013), Vol 34, No. 1, pp. 157-170. Special Issue on "Time and Time Experience," edited by Roberto Ciuni and Guiliano Torrengo. DOI 10.1007/s11245-013-9179-6.

Russell, B. "On the Experience of Time". The Monist. 1915. Repr. in L. N. Oaklander (2008), vol. 1, pp. 174-187. Philosophical Essays. London: George Allen \& Unwin Ltd. 1966. “The Monistic Theory of Truth". 1906-07. In B. Russell (1966) pp. 131-146

"On the Nature of Acquaintance. III Analysis of Experience". The Monist. 1914. Repr. in R. C. Marsh (ed.) (2001), pp. 159-174.

"The Philosophy of Logical Atomism". The Monist, 1918. Repr. in R.

C. Marsh (ed.) (2001), pp. 177-281.

SCHILPp, PAul ARTHur. (ed.) The Philosophy of C. D. Broad. New York: Tudor Publishing Co., 1959.

SIDER, T. Four-Dimensionalism. Oxford: Oxford University Press, 2001.

SMART, J. J. C. "Philosophy and Scientific Realism". London: Routledge \& Kegan Paul, 1963. Partial repr. in L. Nathan Oaklander. (ed.) (2008), vol. 1, pp.187-97.

TEgTMEIER, ERWIN. "McTaggart's error: temporal change." Revue Romaine de Philosophie, pp. 56:89-96, 2012.

Manuscrito - Rev. Int. Fil. Campinas, v. 39, n. 4, pp. 117-156, out.-dez. 2016. 